atmospheric oxygen, measured by David Keeling's son Ralph. Keeling fils showed preliminary results and model simulations at the Snowmass meeting based on his record of atmospheric oxygen initiated at La Jolla in 1989 (ref. 2). The idea is that the ratio of atmospheric $\mathrm{O}_{2}$ to $\mathrm{CO}_{2}$ for a given anomaly depends on whether the anomaly is caused by changes on land or in the ocean. Synthesis of organic matter releases oxygen, and remineralization or burning consumes it in a ratio of about $1: 1$ on land but about $1.4: 1$ in the ocean. Moreover, in the oceans, dissolved $\mathrm{CO}_{2}$ can be taken up into the large inorganic carbon pool through a series of chemical reactions, whereas dissolved oxygen is chemically neutral.

The upshot of this is that an oceanic sink for the Pinatubo anomaly would give an oxygen/carbon dioxide ratio of somewhere between 2 and 8 , whereas a terrestrial sink would give a ratio of about one. In fact, Ralph Keeling's La Jolla observations show a positive Pinatubo oxygen anomaly about twice that of the negative carbon anomaly. So although it is possible that a terrestrial sink is responsible for part of the anomaly, the oxygen data imply that ${ }^{\circ}$ a significant proportion is due to the ocean.

Now we come to the difficult part: what mechanisms could cause the Pinatubo carbon and oxygen anomalies? Answering this question will first require explaining the disagreement between the carbon isotope and oxygen interpretation, but already plenty of speculations have been offered. The El Niño anomalies themselves have yet to be explained satisfactorily. For example, model estimates of the oceanic impact of the 1982-83 El Niño give a carbon uptake anomaly of only $0.8 \mathrm{Pg}$ of carbon ${ }^{3,4}$ as contrasted with an uptake anomaly of $4.5 \mathrm{Pg}$ estimated from the double-deconvolution method ${ }^{1}$. It will be difficult to understand the Pinatubo anomaly without first understanding the background El Niño signal.

At Carqueiranne, Ralph Keeling showed that the anomaly seems to be primarily a Northern Hemisphere effect (Alert at $82^{\circ} \mathrm{N}$ is similar to La Jolla, but Cape Grim data at $41^{\circ} \mathrm{S}$ show no anomaly). His results add a further constraint: he estimates that the Northern Hemisphere oxygen anomaly between May 1991 and the end of 1992 requires a source of about $3 \times 10^{14}$ moles of oxygen to the Northern Hemisphere atmosphere (or a corresponding sink in the Southern Hemisphere). This source is equivalent to a sink of $2.5 \mathrm{Pg}$ of carbon in this time, or $1.5 \mathrm{Pg}$ of carbon a year, if all the oxygen is released by an increase in oceanic photosynthesis. Global oceanic new production today is about $10 \mathrm{Pg}$ of carbon a year.

It is unfortunate that we do not have an ocean colour imager in space at present, as a signal of $1.5 \mathrm{Pg}$ of carbon a year concen- trated in the Northern Hemisphere would almost certainly have been detectable. It would close the problem nicely if an increase in oceanic biological production could also explain the negative Pinatubo carbon anomaly, but there are two problems: first, only a small fraction of the $\mathrm{CO}_{2}$ taken up by an increase in oceanic photosynthesis would come from the atmosphere; second, the carbon-13 data seem to suggest that the carbon anomaly is mostly terrestrial.

The coincidence of the onset of the carbon and oxygen anomalies with the eruption of Pinatubo suggests a causal connection, and one way would be iron fertilization of the oceans. Removal of 2.5 Pg of carbon would require about $0.1 \times 10^{6}$ tonnes of iron. Pinatubo ejected about 3 to $5 \mathrm{~km}^{3}$ of rock equivalent in the form of tephra and pyroclastics 5 ; for a density of $2.8 \mathrm{~g} \mathrm{~cm}^{-3}$ and iron content of about 5 weight per cent, the total iron content is about $500 \times 10^{6}$ tonnes. So only $1 / 5,000$ of the iron would have to be released to organisms in areas of excess surface nutrients (such as nitrates and phosphates) to provide the requisite amount. Another mechanism for a Pinatubo connection is the reduction in sunlight and the cooling caused by the eruption. The reduced radiative forcing due to reflection of light by volcanic aerosols peaks at about $4.5 \mathrm{~W}$ $\mathrm{m}^{-2}$ (ref. 6) compared to the mean supply of $237 \mathrm{~W} \mathrm{~m}^{-2}$.

Cooling accompanied by changes in rainfall could perhaps affect the balance of respiration (a $\mathrm{CO}_{2}$ source) and photosynthesis ( $\mathrm{CO}_{2}$ sink) on land. It could also affect the ocean's capacity to act as a carbon sink, as cooler water takes up more $\mathrm{CO}_{2}$. But Keeling père estimated that this mechanism accounts for only about $0.1 \mathrm{Pg}$ of carbon.

If the anomaly is indeed attributable to the climate effect of Pinatubo, the story becomes still more interesting. We understand so little of the likely response of the carbon cycle to climate change that even discovering the effect of cooling could lead to important insights into the complex feedbacks that will surely be associated with future global warming.

Jorge L. Sarmiento is at the Atmospheric and Oceanic Sciences Program, Princeton University, Princeton, New Jersey 08540. USA.

1. Keeling, C. D. et al in Aspects of Climate Variability in the Pacific and the Western Americas (ed. Peterson, D. H.) 165-236 (Geophys. Monogr. 55, Am. Geophys. Union. Washington DC, 1989)

2. Keeling, R. F. \& Shertz, S. R. Nature 358, 723-727 (1992).

3. Volk, T. Global biogeochem. Cycles 3, 267-279 (1989)

4. Siegenthaler, U. \& Wenk, T. in Ext. Abstr. 3rdint. $\mathrm{CO}_{2}$ Conf Environmental Pollution Monitoring and Research Programme No. 59, 189-194 (World Meteorological Organization. Geneva, 1989).

5. Scott, W. E., Hoblitt, R. P., Daligdig. J. A., Besana, G. \& Tubioanosa, B. S. EOS 72, 61-62 (1991).

6. Hansen, J., Lacis, A., Ruedy, R. \& Sato, M. Geophys. Res Lett. 19, 215-218(1992).

\section{Electric traction}

LAST week Daedalus invented the

converse of a stretch-fabric. Instead of tending to contract in its own plane under an internal surface tension, it tends to expand in its own plane under an internal 'surface compression'. It is woven from conducting wire in such a way that when a current flows, adjacent wires repel each other. The previously slack and flexible fabric then expands tautly, as if it were under tension.

Daedalus intended his new fabric for vacuum-vessels, in which duty its surface expansion could counter the compression of the atmosphere. But such large currents would be needed that only superconducting wire could carry them. So to test the principle, he is weaving more mildly self-tensioning fabrics from normal wire, and is studying their uses.

Already DREADCO tailors have cut out a pair of self-ironing electric trousers. When the current is switched on, the folds and creases of the garment are hauled flat, and it expands taut as if inflated. The way seems open for a military uniform which brings the wearer automatically to attention. Its arms and legs could then be tensioned and relaxed alternately under remote control, thus marching him along semi-automatically at a defined rate. The sergeant-major with the master

transmitter could bring parade-ground precision to the most shambling squad of recruits.

In the home, self-tensioning fabrics could be made into self-straightening carpets, self-closing curtains, and even a self-making bed. Hospitals would welcome such a time saver. The matron could remake all the beds of her ward at the flick of a switch, without even removing the patients. Out of doors, rigid self-erecting hoardings should become feasible, and a self-erecting tent needing no guy-ropes or central pole. It will snap skywards when the current is passed through it, and collapse limply when disconnected.

Stressed-skin engineering structures could benefit as well. An electrically pre-stressed skin could carry compressive and shear loads without further reinforcement. DREADCO engineers are planning boats that need no ribs or stringers, tanks and containers rigid without inflation, and aircraft wings and fuselages with no internal bracing. Even the pneumatic tyre could be redesigned as a self-tensioning structure, needing no inflation and unaffected by punctures. But these serious and fiercely stressed applications need such high internal currents that they must await the coming of room-temperature superconductors.

David Jones 